\title{
Influence of patient gender on mortality after aortic valve replacement for aortic stenosis
}

\author{
Jennifer Higgins, MD, W. R. Eric Jamieson, MD, Osama Benhameid, MD, Jian Ye, MD, \\ Anson Cheung, MD, Peter Skarsgard, MD, Eva Germann, MSc, Florence Chan, and \\ Samuel V. Lichtenstein, MD, PhD
}

Objective: To assess the influence of gender on mortality after aortic valve replacement for aortic stenosis.

Methods: A retrospective analysis was performed on data prospectively collected from all patients undergoing aortic valve replacement for aortic stenosis. Multivariate regression analysis was performed to evaluate the effect of 22 preoperative and operative variables on early, late, and overall mortality.

Results: Aortic valve replacement was performed in 3343 patients with aortic stenosis between 1982 and 2003 . The female patients were older, with a smaller body mass index. The women were less likely to have diabetes, chronic obstructive pulmonary disease, previous myocardial infarction, or left ventricular ejection fraction $<35 \%$ but were more likely to have hypertension or a New York Heart Association III-IV classification. The female patients received a smaller prosthetic valve, with a smaller effective orifice area index (EOAI). The mean follow-up period was $6.18 \pm 4.96$ years, with a total of 2066.142 years of follow-up. The independent predictors of early mortality for the male patients included age, concomitant surgical revascularization, congestive heart failure, and valve size of $\leq 21 \mathrm{~mm}$. The independent predictors of late mortality for the male patients included age, concomitant surgical revascularization, diabetes, renal failure, chronic obstructive pulmonary disease, congestive heart failure, and a bioprosthetic valve. The independent predictors of overall mortality for the male patients included age, concomitant surgical revascularization, diabetes, renal failure, heart failure, and valve size of $\leq 21 \mathrm{~mm}$. For the female patients, the risk factors for early mortality included body mass index $<25 \mathrm{~kg} / \mathrm{m}^{2}$; for late mortality included age, concomitant surgical revascularization, New York Heart Association class III-IV, and diabetes; and for overall mortality included age, concomitant surgical revascularization, New York Heart Association class III-IV, and renal failure. Furthermore, male gender was an independent predictor of late (but not early or overall) mortality.

Conclusions: The independent predictors of mortality after aortic valve replacement for aortic stenosis differed between the male and female patients. Male gender increased the risk of late mortality, and a valve size of $\leq 21 \mathrm{~mm}$ increased the risk of early and overall mortality among the male patients only. These differences need to be taken into consideration preoperatively and require consideration during operative management. (J Thorac Cardiovasc Surg 2011;142:595-601)

\section{Supplemental material is available online.}

\footnotetext{
From the Division of Cardiovascular Surgery, Department of Surgery, University of British Columbia, Vancouver, British Columbia, Canada.

Disclosures: Jian Le reports consulting fees from Edwards. Anson Cheung reports consulting fees from Edwards, Medtronic, and Abiomed. Eric Jamieson reports consulting and/or lecture fees from St. Jude, Medtronic, Sorin, and OnX Life, and grant support from OnX Life, St. Jude, and Medtronic.

Received for publication Jan 30, 2009; revisions received April 29, 2010; accepted for publication May 20, 2010; available ahead of print Jan 19, 2011.

Presented to the Canadian Cardiovascular Society, October 25-29, 2008, Toronto, Ontario, Canada, and Canadian Cardiovascular Society, October 24-28, 2009, Edmonton, Alberta, Canada, and to the Society for Heart Valve Disease, June 27-30, 2009, Berlin, Germany.

Address for reprints: W. R. Eric Jamieson, MD, Vancouver General Hospital, 35002700 Jim Pattison Pavillion, 855 West 12th Avenue, Vancouver, BC V5Z1M9 Canada (E-mail: eric.jamieson@vch.ca).

$0022-5223 / \$ 36.00$

Copyright (C) 2011 by The American Association for Thoracic Surgery doi:10.1016/j.jtcvs.2010.05.056
}

Patient characteristics often differ between males and females with aortic stenosis (AS) who present for aortic valve replacement (AVR). ${ }^{1}$ However, the analysis of the influence of gender on the outcomes in this population has been limited. The objective of the present study was to assess the differences between genders in relation to mortality after AVR for AS.

\section{METHODS}

A retrospective analysis was performed on data prospectively collected from all patients undergoing primary AVR for AS and mixed AS/insufficiency lesions between 1982 and 2003 at the University of British Columbia-affiliated hospitals (Vancouver, British Columbia, Canada: St. Paul's Hospital, Vancouver General Hospital, and Royal Columbian Hospital) The exclusion criteria included previous cardiac surgery. Patients undergoing concomitant coronary artery bypass grafting $(\mathrm{CABG})$ and aortic annulus enlargement were included, as were patients with previous placement of a permanent pacemaker. Only contemporary prosthetic aortic valves were analyzed, including Carpentier-Edwards (SAV, Perimount, Edwards Lifesciences, Irvine, Calif), St. Jude Medical (Standard, HP, Regent, St. Jude Medical, St. Paul, Minn), Medtronic (Mosaic, Medtronic Inc, Minneapolis, 


\author{
Abbreviations and Acronyms \\ AS = aortic stenosis \\ AVR = aortic valve replacement \\ BMI = body mass index \\ $\mathrm{CABG}=$ coronary artery bypass grafting \\ $\mathrm{CHF}=$ congestive heart failure \\ COPD $=$ chronic obstructive pulmonary disease \\ EOA $=$ effective orifice area \\ EOAI = effective orifice area index \\ LVEF $=$ left ventricular ejection fraction \\ NYHA $=$ New York Heart Association
}

Minn), and CarboMedics (Standard, R Series, Top Hat, Sorin-CarboMedics, Denver, Colo). All these valves are currently marketed worldwide, although marketing of the Carpentier-Edwards SAV is limited to North America. (We have previously reported on the clinical performance of this prosthesis in an institutional study and in a joint institutional study. ${ }^{2,3}$ )

AVR was performed in 3343 patients with AS between 1982 and 2003 (2195 men and 1148 women). Both univariate and multivariate logistic regression analyses were performed to evaluate the effect of 22 preoperative and operative variables on early, late, and overall mortality. The univariate variables with $P \leq .25$ were included in the multivariate analyses. The effective orifice area (EOA) index (EOAI) was forced into the multivariate analyses (given the interest in this area among our group). The patients were censored alive at reoperation.

The EOAs in our analyses were determined from the previously published EOAs derived from in vivo echocardiography., ${ }^{2,4}$ The severity of a prosthesis-patient mismatch has been related to the EOAI as follows: normal $\left(\right.$ EOAI $\geq 0.85 \mathrm{~cm}^{2} / \mathrm{m}^{2}$ ), mild to moderate (EOAI $0.65-0.85 \mathrm{~cm}^{2} / \mathrm{m}^{2}$ ), and severe $\left(\mathrm{EOAI} \leq 0.65 \mathrm{~cm}^{2} / \mathrm{m}^{2}\right)$. The standard definitions of mortality outlined by the American Association for Thoracic Surgery were used. ${ }^{5,6}$ Early mortality was defined as all-cause mortality at 30 days after surgery, and late mortality included all-cause mortality $>30$ days.

\section{RESULTS}

The preoperative and operative characteristics of the 3343 patients undergoing AVR for AS are outlined in Table 1. The female patients were older, with a smaller body mass index (BMI). Additionally, the women were less likely to have diabetes, chronic obstructive pulmonary disease (COPD), previous myocardial infarction, or a left ventricular ejection fraction (LVEF) $<35 \%$. However, the women were more likely to have hypertension or a New York Heart Association (NYHA) III-IV classification. The female patients received a smaller prosthetic valve, with a smaller EOA and a smaller EOAI. The women were more likely to undergo aortic annulus enlargement but were less likely to undergo concomitant CABG. The mean follow-up of all patients was $6.18 \pm 4.96$ years, with a total of 2066.142 years of follow-up. The preoperative and operative characteristics comparing the patients by year of surgery and valve type are also listed in Tables $\mathrm{E} 1$ and $\mathrm{E} 2$.

\section{Early Mortality}

The crude early mortality rate for the overall study population was 3.4\% (men $3.0 \%$, and women $4.3 \%, P=.056$ ). From 1982 to 1992 , the crude early mortality rate was $4.1 \%$

TABLE 1. Preoperative and operative characteristics of 3343 patients undergoing aortic valve replacement

\begin{tabular}{lcccc}
\hline \multicolumn{1}{c}{ Characteristic } & Overall $(\mathbf{n}=\mathbf{3 3 4 3})$ & Male $(\mathbf{n}=\mathbf{2 1 9 5})$ & Female $(\mathbf{n}=\mathbf{1 1 4 8})$ & $\boldsymbol{P}$ value $(\mathbf{m a l e}$ vs female) \\
\hline Age $(\mathrm{y})$ & $68.06 \pm 11.20$ & $66.99 \pm 11.39$ & $70.12 \pm 10.53$ & $<.0001$ \\
BMI $\left(\mathrm{kg} / \mathrm{m}^{2}\right)$ & $27.09 \pm 5.13$ & $27.22 \pm 4.79$ & $26.83 \pm 5.73$ & .050 \\
Diabetes mellitus & $10.0 \%$ & $10.8 \%$ & $8.5 \%$ & .039 \\
Hypertension & $23.2 \%$ & $21.6 \%$ & $26.4 \%$ & .002 \\
Renal failure & $9.2 \%$ & $6.0 \%$ & $5.1 \%$ & .326 \\
COPD & $7.8 \%$ & $8.7 \%$ & $6.0 \%$ & .005 \\
Atrial fibrillation & $7.8 \%$ & $7.3 \%$ & $8.7 \%$ & .145 \\
Previous myocardial infarction & $9.2 \%$ & $10.5 \%$ & $6.5 \%$ & .0001 \\
Carotid disease & $0.4 \%$ & $0.5 \%$ & $0.1 \%$ & .043 \\
Previous stroke & $6.3 \%$ & $6.7 \%$ & $5.7 \%$ & .264 \\
Congestive heart failure & $33.8 \%$ & $32.8 \%$ & $35.8 \%$ & .077 \\
NYHA class III-IV & $75.7 \%$ & $74.0 \%$ & $79.0 \%$ & .001 \\
Cardiogenic shock & $0.1 \%$ & $0.046 \%$ & $0.3 \%$ & .087 \\
LVEF $<35 \%$ & $4.3 \%$ & $5.2 \%$ & $2.5 \%$ & $<.001$ \\
Urgency of surgery $(\%$ urgent/emergency) & $91.9 \%$ & $91.6 \%$ & $92.5 \%$ & .369 \\
Valve type $(\%$ bioprosthetic) & $74.6 \%$ & $73.0 \%$ & $77.6 \%$ & .004 \\
Valve size $(m m)$ & $23.24 \pm 2.45$ & $24.17 \pm 2.18$ & $21.44 \pm 1.86$ & $<.0001$ \\
EOA $\left(\mathrm{cm}^{2} / \mathrm{m}^{2}\right.$ ) & $1.60 \pm 0.34$ & $1.71 \pm 0.33$ & $1.39 \pm 0.24$ & $<.0001$ \\
EOAI $\left(\mathrm{cm}^{2} / \mathrm{m}^{2}\right.$ ) & $0.86 \pm 0.17$ & $0.88 \pm 0.17$ & $0.82 \pm 0.15$ & $<.0001$ \\
Concomitant CABG & $43.7 \%$ & $48.2 \%$ & $35.2 \%$ & .0001 \\
Concomitant aortic annulus enlargement & $1.0 \%$ & $0.5 \%$ & $1.7 \%$ & .001 \\
\hline BMI Boy & &
\end{tabular}

$B M I$, Body mass index; $C O P D$, chronic obstructive pulmonary disease; $N Y H A$, New York Heart Association; $L V E F$, left ventricular ejection fraction; $E O A$, effective orifice area; $E O A I$, effective orifice area index; $C A B G$, coronary artery bypass grafting. 
TABLE 2. Univariate analysis for predictors of mortality

\begin{tabular}{|c|c|c|c|}
\hline Variable & $\begin{array}{c}\text { Early } \\
\text { mortality }\end{array}$ & $\begin{array}{c}\text { Late } \\
\text { mortality }\end{array}$ & $\begin{array}{c}\text { Overall } \\
\text { mortality }\end{array}$ \\
\hline \multicolumn{4}{|l|}{ Gender } \\
\hline Female & Referent* & Referent* & Referent* \\
\hline Male & 0.049 & 0.250 & 0.635 \\
\hline Age & $<0.0001$ & $<0.0001$ & $<0.0001$ \\
\hline$\leq 60$ & Referent* & Referent* & Referent* \\
\hline $61-70$ & 0.057 & $<0.0001$ & $<0.0001$ \\
\hline$>70$ & $<0.0001$ & $<0.0001$ & $<0.0001$ \\
\hline BMI & 0.001 & 0.196 & 0.025 \\
\hline$<25 \mathrm{~kg} / \mathrm{m}^{2}$ & Referent* & Referent* & Referent* \\
\hline$\geq 25 \mathrm{~kg} / \mathrm{m}^{2}$ & 0.001 & 0.431 & 0.073 \\
\hline \multicolumn{4}{|l|}{ LVEF } \\
\hline$\geq 35 \%$ & Referent* & Referent* & Referent* \\
\hline$<35 \%$ & 0.33 & 0.00001 & 0.00001 \\
\hline \multicolumn{4}{|l|}{ NYHA class } \\
\hline I & Referent* & Referent* & Referent* \\
\hline II & 0.972 & 0.578 & 0.636 \\
\hline III & 0.459 & 0.409 & 0.295 \\
\hline IV & 0.026 & 0.022 & 0.003 \\
\hline \multicolumn{4}{|l|}{ Dichotomized NYHA class } \\
\hline $\mathrm{I}-\mathrm{II}$ & Referent* & Referent* & Referent* \\
\hline III-IV & 0.011 & 0.00003 & 0.00002 \\
\hline Diabetes mellitus & 0.652 & $<0.0001$ & $<0.0001$ \\
\hline Hypertension & 0.431 & 0.0002 & 0.001 \\
\hline Preoperative atrial fibrillation & 0.013 & 0.001 & 0.0001 \\
\hline Renal failure & $<0.001$ & $<0.0001$ & $<0.0001$ \\
\hline COPD & 0.501 & $<0.0001$ & $<0.0001$ \\
\hline Cardiogenic shock & Not applicable & 0.376 & 0.356 \\
\hline Carotid disease & N/A & 0.580 & 0.781 \\
\hline Myocardial infarction & 0.134 & $<0.0001$ & $<0.0001$ \\
\hline Congestive heart failure & 0.001 & $<0.0001$ & $<0.0001$ \\
\hline \multicolumn{4}{|l|}{ Year of surgery } \\
\hline 1982-1992 & Referent* & Referent* & Referent* \\
\hline 1993-2004 & 0.111 & 0.136 & 0.294 \\
\hline \multicolumn{4}{|l|}{ Status } \\
\hline Elective & Referent* & Referent* & Referent* \\
\hline Urgent & 0.388 & 0.032 & 0.021 \\
\hline Emergent/salvage & 0.001 & 0.007 & $<0.0001$ \\
\hline \multicolumn{4}{|l|}{ Dichotomized status } \\
\hline Elective & Referent* & Referent* & Referent* \\
\hline Urgent/emergent/salvage & 0.266 & 0.023 & 0.011 \\
\hline Valve type bioprosthetic & 0.003 & $<0.0001$ & $<0.0001$ \\
\hline Mechanical & Referent* & Referent* & Referent* \\
\hline \multicolumn{4}{|l|}{ Valve size (mm) } \\
\hline$\leq 21$ & Referent* & Referent* & Referent* \\
\hline$>21$ & $<0.001$ & 0.173 & 0.014 \\
\hline $\operatorname{EOA}\left(\mathrm{cm}^{2} / \mathrm{m}^{2}\right)$ & $<0.001$ & $<0.0001$ & $<0.0001$ \\
\hline EOAI $\left(\mathrm{cm}^{2} / \mathrm{m}^{2}\right)$ & 0.549 & $<0.0001$ & $<0.0001$ \\
\hline \multicolumn{4}{|l|}{ EOAI $\left(\mathrm{cm}^{2} / \mathrm{m}^{2}\right)$} \\
\hline$\geq 0.85$ & Referent* & Referent* & Referent* \\
\hline $0.65-0.85$ & 0.790 & 0.242 & 0.217 \\
\hline$\leq 0.65$ & 0.685 & 0.033 & 0.061 \\
\hline Aortic annulus enlargement & 0.929 & 0.433 & 0.489 \\
\hline $\begin{array}{l}\text { Concomitant coronary artery } \\
\text { bypass grafting }\end{array}$ & $<0.001$ & $<0.001$ & $<0.0001$ \\
\hline
\end{tabular}

(men $3.4 \%$, and women $5.3 \%, P=.126$ ) for the overall population and was $3.0 \%$ (men $2.7 \%$ and women $3.7 \%$, $P=.232$ ) from 1993 to 2004 .

Univariate logistic regression analysis (Table 2 ) revealed increased early mortality for the patients with the following risk factors: female gender, concomitant $\mathrm{CABG}$, increasing age, BMI $<25 \mathrm{~kg} / \mathrm{m}^{2}$, NYHA class III-IV, preoperative atrial fibrillation, renal failure, congestive heart failure (CHF), bioprosthetic valve, valve size of $\leq 21 \mathrm{~mm}$, and emergent status.

Multivariate logistic regression analysis demonstrated that an earlier year of surgery, age $>70$ years, BMI $<25 \mathrm{~kg} / \mathrm{m}^{2}$, CHF, concomitant CABG, valve size of $\leq 21 \mathrm{~mm}$, and urgent/emergent status were independent predictors of early mortality (Table 3). Among the men, age $>70$ years, concomitant $\mathrm{CABG}, \mathrm{CHF}$, and valve size of $\leq 21 \mathrm{~mm}$ all remained independent predictors of early mortality. However, a BMI $<25 \mathrm{~kg} / \mathrm{m}^{2}$ was the only independent predictor of early mortality among the female patients.

\section{Late Mortality}

Univariate logistic regression analysis showed increased late mortality in patients with the following risk factors (Table 2): concomitant CABG, increasing age, EOAI of $\leq 0.65 \mathrm{~cm}^{2} / \mathrm{m}^{2}$, LVEF $<35 \%$, NYHA class III-IV, diabetes, hypertension, preoperative atrial fibrillation, renal failure, COPD, myocardial infarction, $\mathrm{CHF}$, bioprosthetic valve, and urgent or emergent status.

The multivariate hazard regression analysis demonstrated the following independent predictors of late mortality: increased age, concomitant $\mathrm{CABG}, \mathrm{LVEF}<35 \%$, NYHA class III-IV, diabetes, renal failure, COPD, CHF, bioprosthetic valve, and male gender (Table 4). Most of these factors remained predictive of late mortality for the male patients, specifically increased age, concomitant CABG, diabetes, renal failure, COPD, $\mathrm{CHF}$, and bioprosthetic valve. Among the female patients, the only independent predictors of late mortality were increased age, concomitant CABG, NYHA class III-IV, and diabetes.

\section{Overall Mortality}

Compared with late mortality, a valve size of $\leq 21 \mathrm{~mm}$ was the only additional univariate predictor of overall mortality (Table 2). Figure 1 displays the survival for the male and female patients by prosthetic valve size. Among those receiving a prosthetic valve of $\leq 21 \mathrm{~mm}$, the overall mortality was significantly decreased for the male patients $(P=.007)$, with $23.4 \%$ survival at 15 years compared with a rate of $38.3 \%$ for the female patients. No significant difference was seen in overall survival between the men and women receiving a prosthetic valve $>21 \mathrm{~mm}(P=.67)$ (Figure 1). Among the men, survival was significantly decreased with the use of a prosthetic valve of $\leq 21 \mathrm{~mm}$ 
TABLE 3. Multivariate predictors of early mortality

\begin{tabular}{|c|c|c|c|c|c|c|}
\hline & \multicolumn{2}{|c|}{ Early (overall) } & \multicolumn{2}{|c|}{ Male } & \multicolumn{2}{|c|}{ Female } \\
\hline & OR $(95 \%$ CI $)$ & $P$ value & OR $(95 \%$ CI $)$ & $P$ value & OR $(95 \%$ CI $)$ & $P$ value \\
\hline Age $>70 y$ & $4.26(1.81-10.02)$ & .001 & $4.11(1.46-11.58)$ & .007 & - & - \\
\hline $\mathrm{BMI}>25 \mathrm{~kg} / \mathrm{m}^{2}$ & $0.62(0.42-0.92)$ & .018 & - & - & $0.44(0.24-0.82)$ & .009 \\
\hline Congestive heart failure & $1.62(1.06-2.48)$ & .026 & $1.90(1.08-3.36)$ & .026 & - & - \\
\hline Surgical period (1993-2004) & $0.62(0.40-0.95)$ & .030 & - & - & - & - \\
\hline Urgent/emergent status & $3.01(1.10-8.24)$ & .032 & - & - & - & - \\
\hline Valve size $>21 \mathrm{~mm}$ & $0.53(0.33-0.84)$ & .007 & $0.50(0.28-0.92)$ & .025 & - & - \\
\hline $\begin{array}{l}\text { Concomitant coronary artery } \\
\text { bypass grafting }\end{array}$ & $1.91(1.26-2.91)$ & .002 & $2.20(1.22-3.97)$ & .009 & - & - \\
\hline
\end{tabular}

$O R$, Odds ratio; $C I$, confidence interval; $B M I$, body mass index.

compared with a valve size $>21 \mathrm{~mm}(P=.0002)$. This phenomenon was not observed among the women $(P=.392)$.

Figures E1-E4 graphically display the overall survival by gender, age, and LVEF. No significant difference was found in overall survival between the male and female patients $(P=.64)$. Overall survival decreased with increasing age $(P<.0001)$. Overall survival was also significantly decreased for both men $(P<.001)$ and women $(P<.005)$ with a LVEF $<35 \%$.

Multivariate hazard regression analysis revealed that increased age, concomitant $\mathrm{CABG}, \mathrm{LVEF}<35 \%$, NYHA class III-IV, diabetes, renal failure, CHF, and the use of a bioprosthetic valve were predictive of overall mortality (Table 5). For the men, the independent risk factors for overall mortality were increased age, concomitant $\mathrm{CABG}$, diabetes, renal failure, $\mathrm{CHF}$, and valve size of $\leq 21 \mathrm{~mm}$ (Table 5). In contrast, for the women, the independent risk factors for overall mortality included only increased age, concomitant CABG, NYHA class III-IV, and renal failure (Table 5).

\section{DISCUSSION}

Although AVR for AS is performed frequently in cardiac surgery, very few studies have evaluated the predictors of mortality in this population. Furthermore, to the best of our knowledge, no previously published studies have inves- tigated the differences between male and female patients with AS presenting for AVR or their risk factors for mortality after surgery.

At least 5 groups have previously studied the risk factors for early mortality after AVR. ${ }^{7-11}$ However, these populations all included those with pure aortic insufficiency; thus, the relevance to the AS population is somewhat limited. A systematic review that included 28 studies, 16 of which were considered high quality, determined that the only strong predictor for early mortality after AVR was emergent status. ${ }^{7}$ Other moderate predictors of early mortality included increased age, aortic insufficiency, coronary artery disease, increased cardiopulmonary bypass time, decreased LVEF, endocarditis, hypertension, mechanical valves, preoperative pacing, dialysis-dependent renal failure, and an increased valve size. ${ }^{7}$ Our study also demonstrated that age $>70$ years, emergent surgery, renal failure, and concomitant CABG (as a marker of the presence of coronary artery disease) were all predictive of early mortality. However, a BMI $<25 \mathrm{~kg} / \mathrm{m}^{2}$ and a prosthetic valve size of $\leq 21 \mathrm{~mm}$ were also independent predictors of early mortality. Decreased LVEF, hypertension, and valve type were not predictive of early mortality in our population. Other previously demonstrated risk factors for early mortality, such as advanced NYHA class, ${ }^{8}$ preoperative atrial fibrillation, ${ }^{8}$

TABLE 4. Multivariate predictors of late mortality

\begin{tabular}{|c|c|c|c|c|c|c|}
\hline & \multicolumn{2}{|c|}{ Late (overall) } & \multicolumn{2}{|c|}{ Male } & \multicolumn{2}{|c|}{ Female } \\
\hline & HR $(95 \%$ CI $)$ & $P$ value & HR $(95 \%$ CI $)$ & $P$ value & HR $(95 \%$ CI $)$ & $P$ value \\
\hline Male gender & $1.25(1.07-1.45)$ & 0.006 & - & - & - & - \\
\hline Age $61-70$ y & $2.15(1.75-2.65)$ & $<0.0001$ & $2.11(1.67-2.67)$ & $<0.0001$ & $2.35(1.51-3.67)$ & $<0.001$ \\
\hline Age $>70 y$ & $3.87(3.13-4.79)$ & $<0.0001$ & $3.55(2.77-4.54)$ & $<0.0001$ & $4.78(3.06-7.46)$ & $<0.0001$ \\
\hline LVEF $<35 \%$ & $1.41(1.05-1.89)$ & 0.022 & - & - & - & - \\
\hline NYHA III/IV & $1.23(1.04-1.46)$ & 0.014 & - & - & $1.48(1.04-2.10)$ & 0.028 \\
\hline Diabetes mellitus & $1.51(1.18-1.93)$ & 0.001 & $1.43(1.06-1.93)$ & 0.018 & $1.79(1.16-2.75)$ & 0.008 \\
\hline Renal failure & $1.47(1.17-1.85)$ & 0.001 & $1.49(1.13-1.96)$ & 0.005 & - & - \\
\hline COPD & $1.35(1.06-1.72)$ & 0.015 & $1.39(1.04-1.84)$ & 0.024 & - & - \\
\hline $\mathrm{CHF}$ & $1.37(1.18-1.60)$ & $<0.0001$ & $1.48(1.22-1.78)$ & 0.000 & - & - \\
\hline Bioprosthetic valve & $1.26(1.06-1.49)$ & 0.009 & $1.29(1.05-1.58)$ & 0.017 & - & - \\
\hline Concomitant CABG & $1.24(1.09-1.41)$ & 0.001 & $1.20(1.02-1.41)$ & 0.024 & $1.30(1.03-1.65)$ & 0.029 \\
\hline
\end{tabular}

$H R$, Hazard ratio; $C I$, confidence interval; $C H F$, congestive heart failure; other abbreviations as in Table 1. 

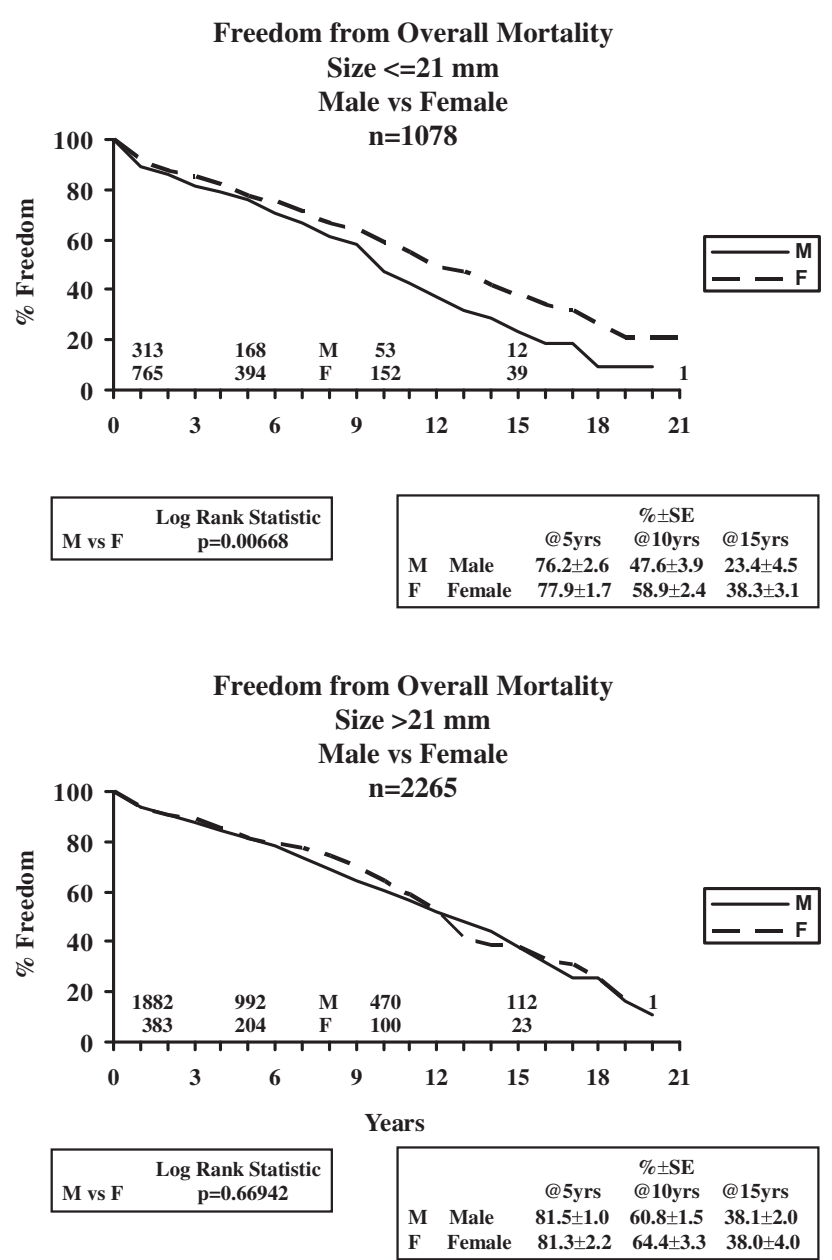

FIGURE 1. Overall survival for men and women stratified by prosthetic valve size. Survival for women was superior to that of men for 15 years for valve size $\leq 21 \mathrm{~mm}(P=.007)$. Survival for women and men was not different for 15 years for valve size $>21 \mathrm{~mm}(P=.669)$. Among men, survival was significantly decreased with a prosthetic valve of $\leq 21 \mathrm{~mm}$ compared with $>21 \mathrm{~mm}(P=.0002)$. Among women, no difference was seen in survival by valve size $(P=.392)$.
$\mathrm{CHF},{ }^{9}$ and diabetes, ${ }^{9}$ were not statistically significant in our multivariate analysis of 3343 patients.

That systematic review also determined that increased age, emergent surgery, and preoperative atrial fibrillation were predictive of late mortality. ${ }^{7}$ Although our analysis revealed increased age as a risk factor for late mortality, neither emergent surgery nor preoperative atrial fibrillation were predictive of late mortality. Furthermore, our study also substantiated that NYHA class III-IV and concomitant CABG were predictive of late mortality. In contrast, the systemic review revealed inconclusive evidence for this claim. ${ }^{7}$ Two other studies investigating late mortality after AVR also demonstrated that coronary artery disease ${ }^{12}$ or concomitant $\mathrm{CABG}^{8}$ and NYHA class IIIB-IV ${ }^{8}$ or $\mathrm{CHF}^{10}$ were risk factors for late mortality. However, these 2 studies also reported atrial fibrillation as predictive of late mortality. ${ }^{8,12}$ Both of these studies were smaller than ours, however, and included patients with pure aortic insufficiency. A recently published study that excluded patients with aortic insufficiency concluded that mortality within this first year was increased for those patients who were older, had had left ventricular dilatation, had received a smaller prosthetic valve, had a calcified ascending aorta, or had had an earlier date of operation. In contrast, increased age, an increased degree of AS, an increased left ventricular mass, a smaller EOAI, left ventricular dysfunction, and moderate to severe symptoms were all predictive of late mortally $>1$ year after AVR. ${ }^{13}$ Most of these variables were not included in our analysis because these data were not available for the earliest group of patients.

Our findings have clearly demonstrated the differences between male and female patients with AS presenting for AVR. The female patients were older, with a smaller BMI, and had a greater incidence of hypertension or NYHA class III-IV, although the male patients were more likely to have diabetes, COPD, previous myocardial infarction, or LVEF $<35 \%$. This increased incidence of

TABLE 5. Multivariate predictors of overall mortality

\begin{tabular}{|c|c|c|c|c|c|c|}
\hline & \multicolumn{2}{|c|}{ Overall } & \multicolumn{2}{|c|}{ Male } & \multicolumn{2}{|c|}{ Female } \\
\hline & HR $(95 \%$ CI $)$ & $P$ value & HR $(95 \%$ CI $)$ & $P$ value & HR $(95 \%$ CI $)$ & $P$ value \\
\hline Age $61-70$ y & $2.08(1.70-2.55)$ & $<.0001$ & $2.08(1.66-2.63)$ & $<.0001$ & $2.29(1.49-3.51)$ & . 000 \\
\hline Age $>70 y$ & $3.80(3.10-4.67)$ & $<.0001$ & $3.63(2.86-4.60)$ & $<.0001$ & $4.64(3.04-7.10)$ & $<.0001$ \\
\hline LVEF $<35 \%$ & $1.36(1.03-1.79)$ & .030 & - & - & - & - \\
\hline NYHA class III-IV & $1.24(1.06-1.46)$ & .007 & - & - & $1.56(1.13-2.15)$ & .007 \\
\hline Diabetes mellitus & $1.41(1.12-1.77)$ & .003 & $1.38(1.04-1.82)$ & .025 & - & - \\
\hline Renal failure & $1.55(1.26-1.91)$ & .000 & $1.26(1.14-1.92)$ & .003 & $1.66(1.15-2.39)$ & .007 \\
\hline CHF & $1.40(1.22-1.61)$ & $<.0001$ & $1.55(1.31-1.84)$ & $<.0001$ & - & - \\
\hline Bioprosthetic valve & $1.22(1.31-1.43)$ & .016 & - & - & - & - \\
\hline Valve size $>21 \mathrm{~mm}$ & - & - & $0.77(0.64-0.93)$ & .006 & - & - \\
\hline Concomitant CABG & $1.33(1.18-1.51)$ & $<.0001$ & $1.25(1.07-1.46)$ & .004 & $1.36(1.10-1.69)$ & .006 \\
\hline
\end{tabular}

Abbreviations as in Tables 1 and 4. 
preoperative co-morbidities in the female patients has been previously demonstrated. ${ }^{1}$ Although female patients would be expected to receive a smaller prosthetic valve, the resulting smaller EOAI and an increased incidence of aortic annulus enlargement were mildly surprising. Female gender was a univariate predictor of early mortality, and male gender was a multivariate predictor of late mortality. Duncan et $\mathrm{al}^{1}$ have also reported female gender as a univariate risk factor for early mortality. However, after propensity matching, they concluded that patient gender was not an independent predictor of in-hospital mortality. ${ }^{1}$ Similarly, Florath and colleagues ${ }^{11}$ demonstrated increased operative mortality in a very select subset of female patients, specifically those receiving AVR and concomitant CABG with a BMI $>29 \mathrm{~kg} / \mathrm{m}^{7}$ At least one study reported male gender as an independent predictor of late mortality in all patients presenting for AVR. ${ }^{14}$ However, a systematic review of the available data claimed the data were insufficient to substantiate gender as an independent predictor of early or late mortality after AVR. ${ }^{7}$

Although many of the previously cited risk factors for mortality were statistically significant for the male patients in our population, the predictors of mortality for the female patients were limited in our study. For the women, a BMI $<25 \mathrm{~kg} / \mathrm{m}^{2}$ was the only independent predictor of early mortality, and increased age, concomitant CABG, NYHA class III-IV, and diabetes were the only predictors of late mortality. Finally, the independent predictors of overall mortality for the women were limited to increased age, concomitant CABG, NYHA class III-IV, and renal failure. Thus, patient gender should be considered when estimating an individual patient's risk of mortality after AVR. These differences in predictors of mortality between men and women were likely due to the innate differences between these 2 genders, as evidenced, in part, by the differences in preoperative characteristics.

Receiving a bioprosthetic valve, instead of a mechanical valve, was a risk factor for both late and overall mortality. Because the patients were censored alive at reoperation, the increased mortality was not related to a second surgery. As expected, the preoperative characteristics differed between the patients receiving bioprosthethic valves compared with those receiving mechanical valves in our study (online Table). However, we have postulated that the increased mortality seen with bioprosthetic valves in the aortic position might have been related to the degenerative changes in the valves, leading to either significant stenosis or regurgitation that might have been missed during late routine patient follow-up. This is an important issue that requires additional investigation and evaluation and was beyond the scope of the present study.

The finding of a valve size of $\leq 21 \mathrm{~mm}$ as a predictor of early and overall mortality in the male patients is an important finding. Thus, the operative management of small annular sizes in male patients needs serious consideration with regard to annular enlargement, the optimal stented or stentless prosthesis, and stentless bioprosthesis root replacement.

The major limitations of the present study were those inherent to a retrospective cohort study. However, every effort was made to ensure complete and accurate information in the database. A second limitation of our study was related to aortic annular enlargement. The decision to perform annular enlargement varies among surgeons; thus, the indications have been inconsistent. However, the number of annular enlargements performed in this patient population was extremely small, making it unlikely to have resulted in a statistically significant effect on mortality. A third limitation was the inter-relationship between BMI, EOA, and prosthesis-patient mismatch. However, despite their interdependency, we believe these remain separate, independent variables. Although an increased BMI increased the risk of severe prosthesis-patient mismatch, a low BMI might be a marker of other risk factors, such as frailty and poor nutrition, which increase the mortality. This could explain how an increased valve size and increased BMI were both protective, but EOAI remained statistically nonsignificant.

\section{CONCLUSIONS}

Men and women with AS presenting for AVR differed with respect to preoperative characteristics, as well as the size of the prosthetic valve and types of concomitant procedures they received. Furthermore, the independent predictors of mortality differed between the male and female patients in this population. Male gender was a risk factor for late, but not early or overall, mortality. These differences between the male and female patients, specifically with regard to valve size, need to be considered preoperatively when attempting to determine the individual patient risks and operative management.

\section{References}

1. Duncan AI, Lin J, Kock CG, Gillinov AM, Xu M, Starr NJ. The impact of gender on in-hospital mortality and morbidity after isolated aortic valve replacement. Anesth Analg. 2006;103:800-8

2. Jamieson WR, Burr LH, Miyagishima RT, Germann E, MacNab JS, Stanford E, et al. Carpentier-Edwards supra-annular aortic porcine bioprosthesis: clinical performance over 20 years. J Thorac Cardiovasc Surg. 2005;130: 994-1000.

3. Jamieson WR, David TE, Feindel CM, Miyagishima RT, Germann E. Performance of the Carpentier-Edwards SAV and Hancock-II porcine bioprostheses in aortic valve replacement. J Heart Valve Dis. 2002;11:424-30.

4. Jamieson WRE, Ye J, Higgins J, Cheung A, Skarsgard P, Fradet GJ, Germann E, Chan F, Lichtenstein SV. Effect of prosthesis-patient mismatch on long-term survival with aortic valve replacement: assessment to 15 years. Ann Thorac Surg. 2010;89:51-9

5. Edmonds LH Jr, Clark RE, Cohn LH, Grunkemeir GL, Miller DC, Weisel RD. Guidelines for reporting morbidity and mortality after cardiac valvular operations: the American Association for Thoracic Surgery, Ad Hoc Liaison Committee for Standardizing Definitions of Prosthetic Heart Valve Morbidity. Ann Thorac Surg. 1996;62:932-5.

6. Akins CW, Miller DC, Turina MI, Kouchoukos NT, Blackstone EH, Grunkemeier GL, et al. Guidelines for reporting mortality and morbidity 
after cardiac valve interventions. J Thorac Cardiovasc Surg. 2008;135: 732-8.

7. Tjang YS, van Heeves Y, Korfer R, Grobbee DE, van der Heijden GJMG. Predictors of mortality after aortic valve replacement. Eur J Cardiothorac Surg. 2007; 321:469-74.

8. Kvidal P, Bergstrom R, Horte L, Stahle E. Observed and relative survival after aortic valve replacement. J Am Coll Cardiol. 2003;35:747-56.

9. Hannan EL, Racz MJ, Jones RH, Gold JP, Ryan TJ, Hafner JP, Isom OW. Predictors of mortality for patients undergoing cardiac valve replacements in New York state. Ann Thorac Surg. 2000;70:121-8.

10. He G, Acuff TE, Ryan WH, Douthit MB, Bowman RT, He Y, Mack MJ. Aortic valve replacement: determinants of operative mortality. Ann Thorac Surg. 1994; 57:1140-6.
11. Florath I, Rosendahl UP, Mortasawi A, Bauer SF, Dalladaku F, Ennker IC, Enker JC. Current determinants of operative mortality in 1400 patients requiring aortic valve replacement. Ann Thorac Surg. 2003;76:75-83.

12. Verheul HA, van den Brink RB, Bouma BJ, Hoedemaker G, Moulijn AC Dekker E, et al. Analysis of risk factors for excess mortality after aortic valve replacement. J Am Coll Cardiol. 1995;26:1280-6.

13. Mihaljevic T, Nowicki ER, Rajeswaran J, Blackstone EH, Lagazzi L, Thomas J, et al. Survival after aortic valve replacement for aortic stenosis: implications for decision making. J Thorac Cardiovasc Surg. 2008;135:1270-9.

14. Cohen G, David TE, Ivanov J, Armstrong S, Fiendel CM. The impact of age, coronary artery disease, and cardiac comorbidity on late survival after bioprosthetic aortic valve replacement. J Thorac Cardiovasc Surg. 1999;117: 273-84.

Access to The Journal of Thoracic and Cardiovascular Surgery Online is reserved for print subscribers!

Full-text access to The Journal of Thoracic and Cardiovascular Surgery Online is available for all print subscribers. To activate your individual online subscription, please visit The Journal of Thoracic and Cardiovascular Surgery Online, point your browser to http://www.mosby.com/jtcvs, follow the prompts to activate your online access, and follow the instructions. To activate your account, you will need your subscriber account number, which you can find on your mailing label (note: the number of digits in your subscriber account number varies from 6 to 10). See the example below in which the subscriber account number has been circled:

\section{Sample mailing label}

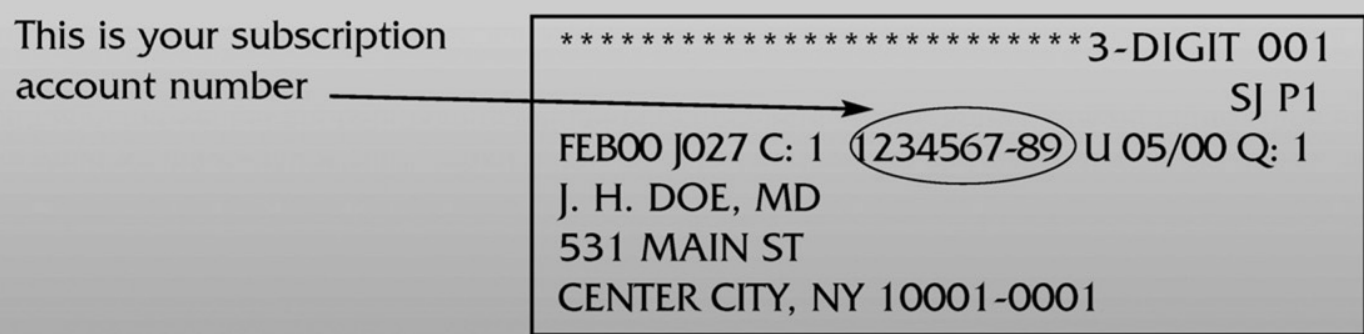

Personal subscriptions to The Journal of Thoracic and Cardiovascular Surgery Online are for individual use only and may not be transferred. Use of The Journal of Thoracic and Cardiovascular Surgery Online is subject to agreement to the terms and conditions as indicated online. 


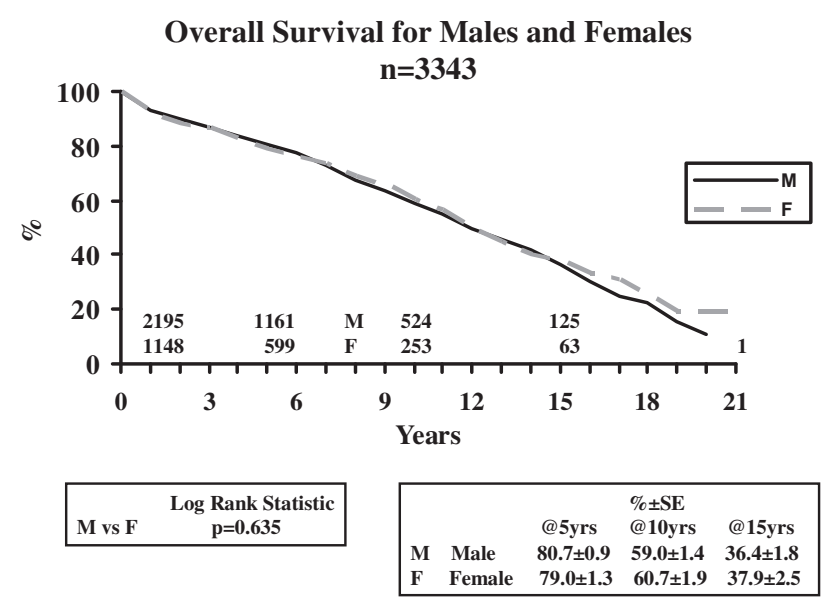

FIGURE E1. Overall survival for men and women. $M$, Males; $F$, females; $S E$, standard error.

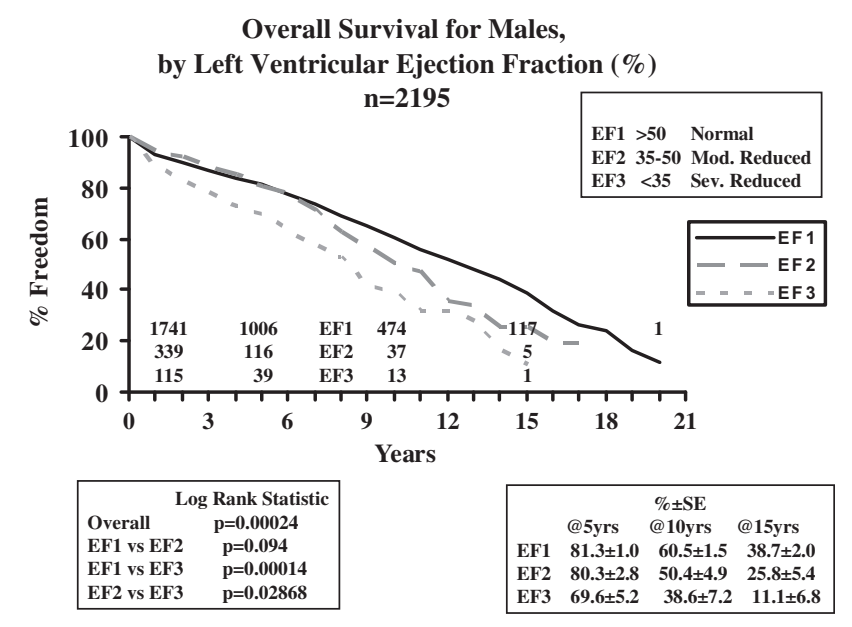

FIGURE E3. Overall survival for men stratified by left ventricular ejection fraction. $E F$, Ejection fraction; $S E$, standard error.

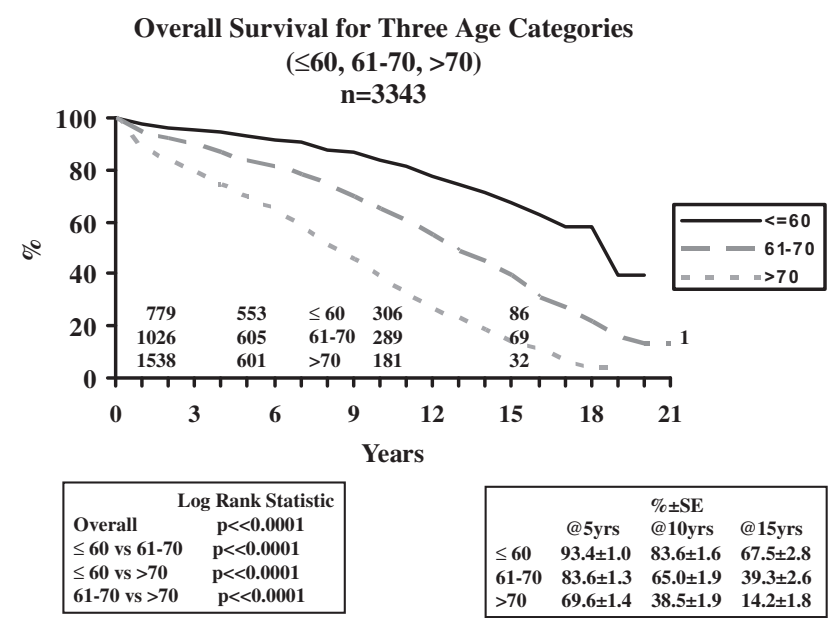

FIGURE E2. Overall survival for 3 age categories. $S E$, Standard error.

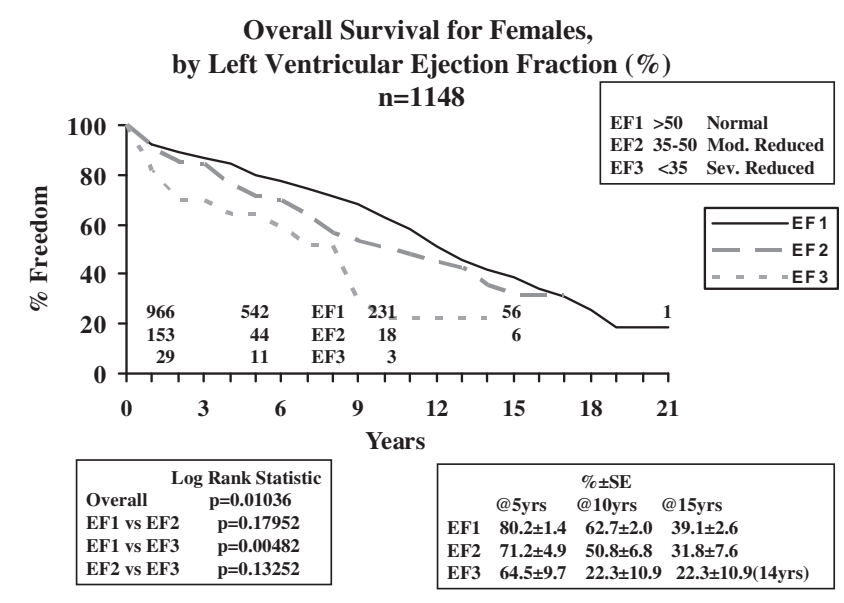

FIGURE E4. Overall survival for women stratified by left ventricular ejection fraction. $E F$, Ejection fraction; $S E$, standard error. 
TABLE E1. Baseline patient characteristics by surgical period

\begin{tabular}{|c|c|c|c|}
\hline Variable & $1982-1992(n=1201)$ & 1993-2004 $(n=2142)$ & $P$ value \\
\hline Follow-up & $9.80(5.18)$ & $4.15(3.44)$ & $<.0001$ \\
\hline Female & $34.5 \%$ & $34.3 \%$ & .905 \\
\hline Age (years) & $66.38(10.89)$ & $69.01(11.26)$ & $<.0001$ \\
\hline Body mass index $\left(\mathrm{kg} / \mathrm{m}^{2}\right)$ & $26.30(5.11)$ & $27.53(5.10)$ & $<.0001$ \\
\hline Diabetes mellitus & $3.0 \%$ & $14.0 \%$ & $<.0001$ \\
\hline Hypertension & $11.8 \%$ & $29.6 \%$ & $<.0001$ \\
\hline Renal failure & $7.5 \%$ & $4.7 \%$ & .001 \\
\hline Chronic obstructive pulmonary disease & $4.3 \%$ & $9.8 \%$ & $<.0001$ \\
\hline Atrial fibrillation & $9.7 \%$ & $6.7 \%$ & .001 \\
\hline Previous myocardial infarction & $5.6 \%$ & $11.2 \%$ & $<.0001$ \\
\hline Carotid disease & $0.2 \%$ & $0.5 \%$ & .154 \\
\hline Previous stroke & $3.2 \%$ & $8.1 \%$ & $<.0001$ \\
\hline Congestive heart failure & $17.5 \%$ & $43.0 \%$ & $<.0001$ \\
\hline New York Heart Association class III-IV & $84.6 \%$ & $70.7 \%$ & $<.0001$ \\
\hline Cardiogenic shock & $0.2 \%$ & $0.1 \%$ & .622 \\
\hline Left ventricular ejection fraction $<35 \%$ & $2.9 \%$ & $5.1 \%$ & .003 \\
\hline Urgency of surgery ( $\%$ urgent/emergency) & $88.1 \%$ & $94.1 \%$ & $<.0001$ \\
\hline Valve type (\% bioprosthetic) & $76.7 \%$ & $73.4 \%$ & .036 \\
\hline Valve size $(\mathrm{mm})$ & $23.58(2.52)$ & $23.04(2.39)$ & $<.0001$ \\
\hline Effective orifice area $\left(\mathrm{cm}^{2} / \mathrm{m}^{2}\right)$ & $1.61(0.30)$ & $1.60(0.36)$ & .117 \\
\hline Effective orifice area index $\left(\mathrm{cm}^{2} / \mathrm{m}^{2}\right)$ & $0.88(0.16)$ & $0.85(0.17)$ & $<.0001$ \\
\hline Concomitant coronary artery bypass grafting & $37.3 \%$ & $47.3 \%$ & $<.0001$ \\
\hline Concomitant aortic annulus enlargement & $0.1 \%$ & $1.4 \%$ & .0001 \\
\hline
\end{tabular}

TABLE E2. Baseline patient characteristics stratified by valve type

\begin{tabular}{|c|c|c|c|}
\hline Variable & Bioprosthetic $(n=2493)$ & Mechanical $(n=2142)$ & $P$ value \\
\hline Follow-up & $5.49(4.91)$ & $8.20(4.52)$ & $<.0001$ \\
\hline Female & $64.3 \%$ & $69.8 \%$ & .004 \\
\hline Age $(y)$ & $71.16(9.45)$ & $58.97(10.98)$ & $<.0001$ \\
\hline Body mass index $\left(\mathrm{kg} / \mathrm{m}^{2}\right)$ & $26.78(4.97)$ & $28.00(5.49)$ & $<.0001$ \\
\hline Diabetes mellitus & $10.8 \%$ & $7.9 \%$ & .016 \\
\hline Hypertension & $26.3 \%$ & $14.4 \%$ & $<.0001$ \\
\hline Renal failure & $6.5 \%$ & $3.3 \%$ & .0005 \\
\hline Chronic obstructive pulmonary disease & $9.0 \%$ & $4.2 \%$ & $<.0001$ \\
\hline Atrial fibrillation & $6.9 \%$ & $10.5 \%$ & .001 \\
\hline Previous myocardial infarction & $10.6 \%$ & $4.9 \%$ & $<.0001$ \\
\hline Carotid disease & $0.4 \%$ & $0.4 \%$ & 1 \\
\hline Previous stroke & $7.4 \%$ & $3.2 \%$ & $<.0001$ \\
\hline Congestive heart failure & $36.3 \%$ & $26.5 \%$ & $<.0001$ \\
\hline New York Heart Association class III-IV & $78.2 \%$ & $68.5 \%$ & $<.0001$ \\
\hline Cardiogenic shock & $0.1 \%$ & $0.2 \%$ & .269 \\
\hline Left ventricular ejection fraction $<35 \%$ & $4.5 \%$ & $3.9 \%$ & .48 \\
\hline Urgency of surgery ( $\%$ urgent/emergency) & $93.0 \%$ & $88.7 \%$ & .0001 \\
\hline Valve type ( $\%$ bioprosthetic) & $63.1 \%$ & $67.1 \%$ & .036 \\
\hline Valve size $(\mathrm{mm})$ & $23.18(2.44)$ & $23.39(2.47)$ & .035 \\
\hline Effective orifice area $\left(\mathrm{cm}^{2} / \mathrm{m}^{2}\right)$ & $1.54(0.25)$ & $1.79(0.47)$ & $<.0001$ \\
\hline Effective orifice area index $\left(\mathrm{cm}^{2} / \mathrm{m}^{2}\right)$ & $0.84(0.13)$ & $0.93(0.23)$ & $<.0001$ \\
\hline Concomitant coronary artery bypass grafting & $48.5 \%$ & $29.6 \%$ & .504 \\
\hline Concomitant aortic annulus enlargement & $1.0 \%$ & $0.7 \%$ & $<.0001$ \\
\hline
\end{tabular}

